\title{
Resistance of diamondback moth to insecticides in selected cabbage farms in southern Ghana
}

\author{
Jacinter A.O. ODHIAMBO ${ }^{1}$, Winfred S.K. GBEWONYO ${ }^{1,2^{*}}$, Daniel OBENG- OFORI ${ }^{1,3}$, \\ Michael D. WILSON ${ }^{4}$, Daniel A. BOAKYE ${ }^{4}$ and Charles BROWN ${ }^{4}$ \\ ${ }^{1}$ African Regional Postgraduate Programme in Insect Science, University of Ghana, P.O. Box LG 82, Legon, \\ Accra, Ghana. \\ ${ }^{2}$ Department of Biochemistry, University of Ghana, P.O. Box LG 54, Legon, Accra, Ghana. \\ ${ }^{3}$ Crop Science Department, University of Ghana, P.O. Box LG 44, Legon, Accra, Ghana. \\ ${ }^{4}$ Noguchi Memorial Institute for Medical Research, University of Ghana, P. O. Box LG 581, Legon, Accra, \\ Ghana. \\ *Corresponding author, E-mail:wsgbew@ug.edu.gh;Tel:-0233-243318390
}

\begin{abstract}
Resistance of diamondback moth (DBM), Plutella xylostella (L.) to insecticides applied for its control on cabbage was evaluated. DBM populations were tested for susceptibility to three pyrethroids (delatamethrin, lambdacyhalothrin, cypermethrin) and an organophosphate (chlorpyrifos-methyl) insecticide using larvae immersion dose-response technique. Non-specific carboxylesterase activity was used as a measure of DBM resistance. Partial characterization of carboxylesterase by zymogram studies was also undertaken using polyacrylamide gel electrophoresis (PAGE). Susceptibility studies revealed that DBM was resistant to the four insecticides assayed. DBM was least susceptible to chlorpyrifos-methyl, but most susceptible to deltamethrin. Esterase zymogram studies revealed between 2 to 7 bands, each with different characteristics. Higher frequency of the slow-moving esterases associated with high resistance was recorded in Mampong DBM population than the Accra suburbs. This finding confirmed results for carboxylesterase activity. Deltamethrin and cypermethrin demonstrated high negative correlation between fold resistance and carboxylesterase activity for $\beta$-isozyme. Chlorpyrifos-methyl, on the other hand showed positive correlation between fold resistance and $\alpha$-carboxylesterase activity. The high carboxylesterase activities recorded for Mampong DBM, however, did not correlate with results of susceptibility studies. It is suggested that farmers should adopt an integrated approach using the IPM principles coupled with judicious use of biopesticides such as Bacillus thuringiensis. (C) 2010 International Formulae Group. All rights reserved.
\end{abstract}

Keywords: Susceptibility, Plutella xylostella, organophosphates; pyrethroids; carboxylesterases

\section{INTRODUCTION}

In Ghana, the cultivation and consumption of cabbage has been on the increase especially in the urban areas where there is high demand for the vegetable. The diamondback moth (DBM), Plutella xylostella
(L.) is one of the most important pests of the Brassicacea crops including cabbage. This insect is believed to be the most universally distributed of all Lepidopterans. Out of the 191 countries worldwide, DBM is listed to be 
present in 145 countries scattered over all possible climatic and ecogeographical zones (Pichon et al., 2006). Among all the control methods the use of chemicals is the most effective and convincing, optimizing crop yields and improving quality of farm produce (GTZ, 1979). Brempong-Yeboah (1992) observed that cabbage growers in Accra plains used unnecessarily large quantities of insecticides, and in various concoctions against DBM. Large scale and indiscriminate use of insecticides for the control of this pest, necessitated by the ever increasing demand for quality food and better public health has resulted in insecticide resistance and also health hazards due to toxic residues (Joia et al., 2004). Therefore DBM's control by conventional insecticides as well as the biopesticide Bacillus thuringiensis has become more difficult due to the development of resistance to these agents. Insecticide resistance in DBM has occurred in many parts of the world. Resistance has been reported in Hawaii (Tabashnik et al., 1987), Japan and Australia (Kao et al., 1989) and China (Kao and Cheng, 2001).

Diamondback moth resistance covers a wide range of insecticides including all the major groups of insecticides - chlorinated hydrocarbons, organophosphorus insecticides, carbamates and synthetic pyrethroids (Kao and Cheng, 2001) and even some bacterial pesticides, such as Bacillus thuringiensis (B.t.) based products (Wright et al., 1997), as well as insect growth regulators (YuXian, 2001). Resistance mechanisms in DBM proposed for synthetic chemicals include decreased penetration (Noppun et al., 1987), enhanced detoxification by esterases (Maa and Chuang, 1983), glutathione-S-transferases and reduced sensitivity of acetylcholinesterase (Hama, 1987). Eziah et al. (2008) have suggested based on a study on susceptibility of field populations of DBM to six selected insecticides, the involvement of esterases and/or monooxygenases as the key resistance mechanism. A recent study by Moharil et al. (2008) of the role of carboxylesterases in cypermethrin resistance has led to the development of a rapid detection kit for monitoring/detection of carboxylesterasemediated resistance mechanism in DBM. In Ghana carboxylesterase activity was used as a measure of DBM resistance (Kaiwa, 2000). This study therefore aims at the evaluation of the activity of carboxylesterase in DBM, and the use of bioassay and electrophoretic zymogram studies to ascertain the existence of resistance in DBM populations in Ghana.

\section{MATERIALS AND METHODS}

The following pyrethroids [Lamdacyhalothrin (Pawa 2.5 EC), Deltamethrin (Deltaplan 12.5 EC) and Cypermethrin (Cypercal 250 EC)) and one organophosphate (Chlorpyrifos-methyl (Dursban 4 EC)] were selected for the bioassay based on surveys that had been conducted (Ninsin, 1997; Odhiambo, 2005).

\section{Sampling and culturing of diamondback moth}

Diamondback moth was mass reared in the laboratory to obtain uninterrupted supply of physiologically homogeneous insects. Wild $4^{\text {th }}$ instar larvae and pupae were collected from infested cabbage farms in three different locations, which are suburbs of Accra, namely Madina $\left(05^{\circ} 40.36 \mathrm{~N}, 00^{\circ} 10.24 \mathrm{~W}\right)$, Airport $\left(05^{\circ} 35.72 \mathrm{~N}, 00^{\circ} 10.89 \mathrm{~W}\right)$ and Dzorwulu $\left(05^{\circ}\right.$ $\left.37.05 \mathrm{~N}, \quad 00^{\circ} \quad 11.70 \mathrm{~W}\right)$ and MampongAkwapem $\left(05^{\circ} 24.74 \mathrm{~N}, 00^{\circ} 36.25 \mathrm{~W}\right)$. The larvae were preserved at $-80{ }^{\circ} \mathrm{C}$ and later used for enzyme assay. A colony of DBM was also established in rearing cages $\left(30 \mathrm{~cm}^{3}\right)$ in a screen-house at temperature of $28 \pm 2{ }^{\circ} \mathrm{C}$ with relative humidity of $65-70 \%$ and a photoperiod of $12 \mathrm{~h}: 12 \mathrm{~h}$ (L:D). The method of rearing was modified from Liu and Sun (1984) and Osae (2002), in which the adult moths were sustained on cotton wool impregnated with $50 \%(\mathrm{v} / \mathrm{v})$ honey solution and potted insecticide-free cabbage seedlings provided for oviposition and feeding of the larvae. To obtain larvae of uniform age, oviposition was synchronized by leaving every potted cabbage in the oviposition cage for 24 h. Early $4^{\text {th }}$ instar larvae from F1 and F2 generations were tested for susceptibility 
to the range of insecticides used for the bioassays.

\section{Determination of level of resistance}

Various methods were employed to determine the resistance of DBM to the selected insecticides. Larvae immersion bioassay protocol was adopted from Zhao et al. (1994) with slight modification. Half-cone shaped plastic cups (depth, about $2.74 \mathrm{~cm}$ ) with both ends open were improvised for bioassay. The wide bottom end (radius 3.42 $\mathrm{cm}$ ) was fitted with fine netting material while the top end (radius $2 \mathrm{~cm}$ ) was left open. Serial dilutions of the insecticides below and above their recommended dosages chlorpyrifos: 3 g/L, cypermethrin: $0.1 \mathrm{~g} / \mathrm{L}$, deltamethrin: $0.0375 \mathrm{~g} / \mathrm{L}$ and lambda-cyhalothrin: $0.083 \mathrm{~g} / \mathrm{L}$ were prepared in Petri dishes. For each dilution, ten early fourth larval instars were placed on the net inside the cup and immersed in the test solutions in the Petri dish for 2 seconds. Cabbage leaves were provided for food and parafilm was used to seal the top open end of the cup. Mortality data was recorded every $12 \mathrm{~h}$ for three days. Any larva that did not respond to pencil-tip prodding was considered dead.

For the control, the larvae-containing cups were dipped in distilled water and provided with cabbage leaves. Whenever the control mortality exceeded 20 per cent, the data was rejected and fresh batch of larvae were used for the treatment. To help predict field performance using laboratory data, discriminating concentration method for resistance monitoring was used for comparison of concentration - mortality tests (Zhao et al., 1994). The data for each replicate were pooled and analyzed by probit analysis (Finney, 1971), using MINITAB software programme to determine lethal concentration (LC) values at $50 \%$ and $95 \%$ levels at $95 \%$ confidence intervals (CI). The slope of the regression line was also recorded. When a resistant strain was established, cross- and multiple-resistance were evaluated to determine which insecticides could be used to manage the resistant DBM populations. The protocol was modified from Ninsin (2004).
Survivals from the bioassay were reared to adults and their F1 generation used to test for cross- and multiple-resistance. Recommended dosages of other insecticides, not used for resistance selection on the parents, were tested using larvae immersion bioassay as described above.

\section{Carboxyl esterase activity in field population of DBM}

Hydrolytic activities of non-specific esterases were determined with two model substrates, $\alpha$ - and $\beta$-naphthyl acetate at predetermined optimum substrate concentration $(30 \mathrm{mM})$, temperature $\left(40{ }^{\circ} \mathrm{C}\right)$ and $\mathrm{pH}$ value (7.2) (Kaiwa, 2000). DBM specimens were assayed for carboxylesterase activity by naphthyl acetate-diazo blue coupling reaction (Owusu, 1992). A standard curve was obtained and used as reference.

\section{Standard curves for $\alpha$ - and $\beta$-naphthol}

A $0.2 \mathrm{M}$ solution of $\alpha$-naphthol (MW 144.2) in $10 \mathrm{ml}$ of absolute ethanol was initially prepared. From this the following serial dilutions were obtained: $10 \times 10^{-4} \mathrm{M}, 5 \mathrm{x}$ $10^{-4} \mathrm{M}, 2.5 \times 10^{-4} \mathrm{M}, 1.25 \times 10^{-4} \mathrm{M}, 6.25 \times$ $10^{-5} \mathrm{M}$, by diluting with absolute ethanol in test tubes. A test tube containing ethanol (0.1 $\mathrm{ml})$ was also set up as a blank. The different concentrations were then used to establish the calibration curve. Into each of the five test tubes containing $2.8 \mathrm{ml}$ of $0.07 \mathrm{M}$-phosphate buffer ( $\mathrm{pH} 7.2$ ), was added separately $0.1 \mathrm{ml}$ of the prepared $\alpha$-naphthol solution. Sodium dodecylsulfate fast blue B salt (SDS-FBS) solution $(0.5 \mathrm{ml})$ was added to each test tube and the mixture incubated for 15 minutes for colour development. The absorbance was measured using a Shimadzu Double-beam spectrophotometer at $600 \mathrm{~nm}$ against a blank that had $\alpha$-naphthol being replaced by absolute ethanol. Likewise a $0.5 \mathrm{M}$ solution of $\beta$-naphthol (MW 144.2) in $10 \mathrm{ml}$ of absolute ethanol was prepared. This solution was serially diluted 1 in 10 to give a concentration of $5 \times 10^{-3} \mathrm{M}$. This concentration was further serially diluted 1 in 2 to obtain the concentrations $25 \times 10^{-4}, 12.5 \times 10^{-4}, 6.25 \times$ $10^{-4}, 3.125 \times 10^{-4} \mathrm{M}$ in test tubes. The buffer was added and colour development carried out 
as stated above. The absorbance was measured at $450 \mathrm{~nm}$ against the blank that had $\beta$-naphthol being replaced by absolute ethanol. The absorbances of the sample measurements were converted to micromoles of $\beta$-naphthol produced by reference to the standard curve. The calibration curve was obtained using linear regression in MINITAB statistical software programme.

\section{Calibration curve of bovine serum albumin (BSA)}

Serial dilutions ranging between 0.1 $\mathrm{mg} / \mathrm{ml}$ and $6.25 \times 10^{-3} \mathrm{mg} / \mathrm{ml}$ obtained from $0.1 \%$ BSA stock solution were used to establish the calibration curve. To $0.1 \mathrm{ml}$ sample of BSA was added $2 \mathrm{ml}$ of the following - "Protein reagent mixture": [50 ml of alkaline sodium carbonate solution (2\% w/v, $\mathrm{Na}_{2} \mathrm{CO}_{3}$ in $0.1 \mathrm{M} \mathrm{NaOH}$ ), plus $0.5 \mathrm{ml}$ each of $\mathrm{CuSO}_{4}\left(4.04 \times 10^{-2} \mathrm{M}\right)$ and sodium tartrate $\left.\left(4.35 \times 10^{-2} \mathrm{M}\right)\right]$. This mixture was incubated in a test tube at room temperature $\left(30 \pm 2{ }^{\circ} \mathrm{C}\right)$ for 20 minutes for colour development, and absorbance read at $750 \mathrm{~nm}$ against a blank that lacked BSA solution.

\section{Enzyme preparation and assay}

Individual larvae were homogenized using sterilized plastic pestle in a 1.5 Eppendorf tube containing $0.3 \mathrm{ml}$ of potassium phosphate buffer $(\mathrm{pH}$ 7.2). The resultant homogenate was centrifuged at 4000 rpm in an Eppendorf centrifuge 5415C for 2 min at 1 min interval and was then used as enzyme source for carboxylesterase assay. The reaction mixture consisted of incubating $0.1 \mathrm{ml}$ of the homogenate with $0.1 \mathrm{ml}$ of 30 $\mathrm{mM} \alpha$-naphthyl acetate, in absolute ethanol for $10 \mathrm{~min}$. at $40{ }^{\circ} \mathrm{C}$ in $2.8 \mathrm{ml}$ of phosphate buffer ( $\mathrm{pH}$ 7.2) in a shaking water bath. After incubation, $0.5 \mathrm{ml}$ of SDS-FBS was added for colour development. This mixture was incubated for $15 \mathrm{~min}$ and read at $600 \mathrm{~nm}$ with a spectrophotometer against a control that lacked enzyme. The homogenate $(0.1 \mathrm{ml})$ was also incubated for $10 \mathrm{~min}$ at $40{ }^{\circ} \mathrm{C}$ with $\beta$ naphthyl acetate in absolute ethanol as substrate. The mixture was incubated with SDS-FBS for 15 minutes to allow colour development after which it was read at 450 $\mathrm{nm}$ with spectrophotometer against a control that lacked the enzyme. For DBM larvae with higher activity above the measurable range, the homogenate was appropriately diluted 1 in 10 with phosphate buffer before assay.

\section{Protein determination}

Protein contents of all enzyme preparations used were determined by the method of Lowry et al. (1951) as adapted by Kaiwa (2000) with slight modifications. Aliquots $(0.1 \mathrm{ml}$ portions $)$ of the homogenized enzyme solution were transferred into test tubes and $2 \mathrm{ml}$ of the "Protein Reagent Mixture" described earlier was added to it. This mixture was allowed to stand for about 30 minutes. Freshly prepared $(0.25 \mathrm{ml})$ dilute phenol reagent [Folin-Ciocalteau reagent: water, 1:1] was then added and the reaction mixture was incubated for further $20 \mathrm{~min}$ to allow for a blue colour development. Readings were taken on a spectrophotometer at $750 \mathrm{~nm}$ against a control that lacked an enzyme source.

\section{Polyacrylamide gel electrophoretic analysis of DBM esterase isozymes}

Even though the hydrolytic enzymes have been quantified and documented, polyacrylamide gel electrophoresis can be used to further characterize the esterase enzyme based on the band sizes, electrophoretic mobilities and staining intensity of different isozymes. The method was a modification from Siegfried and Scott (1991).

Each insect was homogenized in $33 \mathrm{ml}$ of sample buffer using sterilized plastic pestle in a $1.5 \mathrm{ml}$ Eppendorf tube to break the cells and centrifuged at $4000 \mathrm{rpm}$ in an Eppendorf centrifuge $5415 \mathrm{C}$ for $15-20$ minutes and the supernatant was used for electrophoresis.

Non-denaturing discontinuous $(2.5 \%$; $7 \%$ ) polyacrylamide gel electrophoresis (PAGE) was performed in Tris-glycine buffer ( $\mathrm{pH}$ 8.3) with slab plate (ATTO CORPORATION, Japan). Fifteen millilitres of supernatant was loaded along with $50 \mathrm{~g}$ sucrose in running buffer at $\mathrm{pH} 8.9$, into wells of the polymerized stacking gel. The electrophoresis was conducted at a constant 
voltage of $150 \mathrm{~V}$ supplied by an electrophoresis power supply pack ATTO AE3121 (ATTO CORPORATION, Japan) until the tracking dye had moved to the interface between the stacking gel and separating gel.

Staining of the gel for protein bands corresponding to esterase activity was done in a plastic tray containing staining solution [(100 ml of $0.2 \mathrm{M}$ phosphate buffer, $\mathrm{pH} \mathrm{6)}$ containing $2 \mathrm{ml} \alpha$-naphthyl acetate $(30 \mathrm{mM})$ and $0.2 \mathrm{~g}$ fast blue $\mathrm{BB}$ salt], at room temperature in the dark for 45 minutes. After the protein bands appeared, the gel was transferred from the staining solution into the fixing solution (7\% acetic acid) overnight in a slow mechanical shaker to destain the background. The destained gel was then visualized under an ordinary light illuminator and stored in distilled water to prevent it from drying up. While still soaked in distilled water, the destained gel was transferred onto chromatographic filter papers $3 \mathrm{~mm}$ thick (Tokyo Roshi Kaishi, Ltd, Tokyo, Japan) and overlaid with a cellophane membrane previously softened by immersion in distilled water then left to dry over a flat hard board for 3 days.

\section{RESULTS}

\section{Susceptibility of DBM to insecticides}

Diamondback moth was found to be resistant to all the insecticides assayed. Dose response mortality curves were used to determine the $\mathrm{LC}_{50}$ and $\mathrm{LC}_{95}$ values. The $\mathrm{LC}_{95}$ values were found to be much higher than the recommended dosage for all the insecticides assayed, which included Dursban (chlorpyrifos-methyl), Deltaplan (deltamethrin), Pawa (lambda-cyhalothrin) and Cypercal (cypermethrin) (Table 1). For all the study sites, it was observed that DBM was most susceptible to deltamethrin, since the slopes obtained indicated that deltamethrin demonstrated the highest rate of lethal toxicity to DBM, and chlorpyrifos-methyl, the least rate of lethal toxicity.

Pawa (lambda-cyhalothrin): The $\mathrm{LC}_{95}$ estimated for Pawa for the Airport population was $8527.3 \mathrm{mg} / \mathrm{L}$ which when compared with the recommended dosage of $83 \mathrm{mg} / \mathrm{L}$, gave
102.7 fold resistance. The Dzorwulu population of DBM followed closely with 100.3 fold resistance and the least resistant population was at Mampong which recorded 57.9 fold resistance (Table 1). Pawa was the most highly resisted pyrethroid in all the sites and in terms of overall activity; it was only second to dursban in all the study sites. Cypercal (cypermethrin): Airport DBM population showed the highest level of resistance to Cypercal, recording $\mathrm{LC}_{95}$ of $8565.2 \mathrm{mg} / \mathrm{L}$ which when compared to the recommended dosage of $100 \mathrm{mg} / \mathrm{L}$, gave 85.7 fold resistance (Table 1). Other Accra suburb sites recorded nearly similar values of fold resistance. Mampong, however, recorded the lowest which was 54.6 fold resistance. Deltaplan (deltamethrin): This was shown to be the most effective of all the pyrethroids assayed. Among the conventional insecticides it had the lowest $\mathrm{LC}_{95}$ value in all the sites. However of all the sites, it was least effective in Dzorwulu where DBM population recorded an $\mathrm{LC}_{95}$ value of $3.0 \times 10^{3} \mathrm{mg} / \mathrm{L}$ against a critical dosage of $37.5 \mathrm{mg} / \mathrm{L}$ giving, 79.7 fold resistance (Table 1). Dursban (chlopyrifosmethyl): The bioassay revealed that chlorpyrifos-methyl was the least effective of all the insecticides assayed. It generally recorded the highest $\mathrm{LC}_{95}$ value in all the sites, except for Madina, and also recorded the highest fold resistance. Specifically, Dzorwulu DBM population proved to be the most resistant to Chlorpyrifos-methyl with $\mathrm{LC}_{95}$ of $5.8 \times 10^{5} \mathrm{mg} / \mathrm{L}$ against recommended dosage of $3.0 \times 10^{3} \mathrm{mg} / \mathrm{L}$ giving a 193.2 fold resistance (Table 1). The Madina DBM population was comparatively less resistant.

\section{Cross- and multiple-resistance}

The DBM larvae were shown to have developed cross-resistance to the commonly used pyrethroids and multiple-resistance to the pyrethroids and organophosphates. These phenomena were tested across some selected sites. The DBM population that resisted Pawa could be fairly controlled by dursban in Madina, where 42 out of $80(52 \%)$ mortality was recorded. Similar populations were resistant to dursban in Mampong and Airport 
where only $21(26 \%)$ and $24(30 \%)$ out of 80 mortalities were recorded for both sites respectively. The DBM population resistant to Pawa when exposed to deltaplan at Airport recorded only 21 (30\%) mortality. However, Deltaplan resistant DBM population at the same site gave mortality of $8(10 \%)$ for Dursban. Conversely, when selection was done using Dursban and the population exposed to Pawa, mortalities ranging from 12 to $32(15-40 \%)$ were recorded in all the study sites. There was however $90 \%$ mortality recorded in the DBM population selected for resistance by all the conventional insecticides bioassayed when exposed to Bacillus thuringiensis.

\section{Carboxylesterase activity in field populations of diamondback moth}

For each of the seven sub-study sites, 25 samples of DBM larvae were assayed for the two enzymes $\alpha$ - and $\beta$-carboxylesterases. The study sites were Mampong-Akuapem, Madina, Airport and Dzorwulu.

\section{a-naphthyl esterase}

The highest level of activity for $\alpha$ naphthyl esterase was recorded in Mampong (Table 2). The Mampong DBM population gave activity, which was significantly different from all the other sites $(\mathrm{P}<0.05)$. However the activity recorded for Madina was not significantly different from that of Dzorwulu and Airport.

\section{$\beta$-naphthyl esterase}

$\beta$-naphthyl esterase activity for Mampong DBM population was found to be very high while much lower activities were recorded for Accra subsites. Comparatively, higher activities were recorded in Madina.

In general, Mampong DBM population was found to show the widest disparity in activity for both enzymes. With regard to the insecticides used in cabbage farms, lambdacyhalothrin formulations (ie. Pawa) was found to have been used by farmers in all the study sites (Odhiambo, 2005). Bioassay showed DBM population in Mampong to be the most susceptible to Pawa (Table 1). Although chlorpyrifos-methyl (dursban) was also used in all the farms, susceptibility studies showed
Dzorwulu DBM samples to be the least susceptible to dursban while the Madina populations were the most susceptible to dursban. For the Accra surburbs, there was some correlation between fold resistance of DBM to some of the insecticides and the mean carboxylesterase activity for the different sites (Table 3). Very little relationship existed between fold resistance to cypercal (cypermethrin) and both $\alpha$-esterase $(r$ $=-0.56)$ and $\beta$-esterase $(r=-0.38)$ activities. Alpha-esterase activities were generally positively correlated, while beta-esterase activities were negatively correlated, with fold resistance (Table 3). Pawa (lambdacyhalothrin) showed good negative correlation for $\beta$-esterase $(r=-0.90)$. On the other hand, fairly high level of correlation was found for Dursban (chlorpyrifos-methyl), $\alpha$ esterase $(r=0.83)$ and $\beta$-esterase $(r=-0.92)$ and Deltaplan (deltamethrin), $\alpha$-esterase $(r=$ $0.65)$ and $\beta$-esterase $(r=-0.99)$.

\section{Native polyacrylamide gel electrophoresis (PAGE)}

Various distinct banding patterns were revealed in the field populations of DBM. The variants were classified based on the number of bands, staining intensity, and electrophoretic mobility. Between two to seven bands were detected in the zymograms. These bands were scattered throughout two zones of the gel: a fast moving upper zone and a slightly slower moving middle zone (Figure 1). The fast moving zone, composed of one narrow and one wide band, was detected in all the zymograms examined. The middle zonebands, however, varied in number, width, and staining intensity, with some faint bands in front of the main body of the middle zone, being present in most of the zymograms.

The heterogeneous nature of the esterases was shown through polymorphism of isozyme patterns and general variations. Thus more than one zymogram pattern was observed for DBM larvae even within the same populations (Figure 1). The electrophoregram revealed higher frequency of slow moving esterases, which confer more resistance in Mampong samples (Figure 2) 
than for the Accra suburb sites which had majority of the zymograms with the fast moving esterases which are associated with less resistance. Besides, the zymogram patterns for the Accra populations were relatively similar, compared with the
Mampong population, which reflected a wide range of zymogam patterns. Among the Accra populations Madina samples had relatively higher frequency of the slow moving esterases and the site with the least frequency of this type of esterase was Dzorwulu.

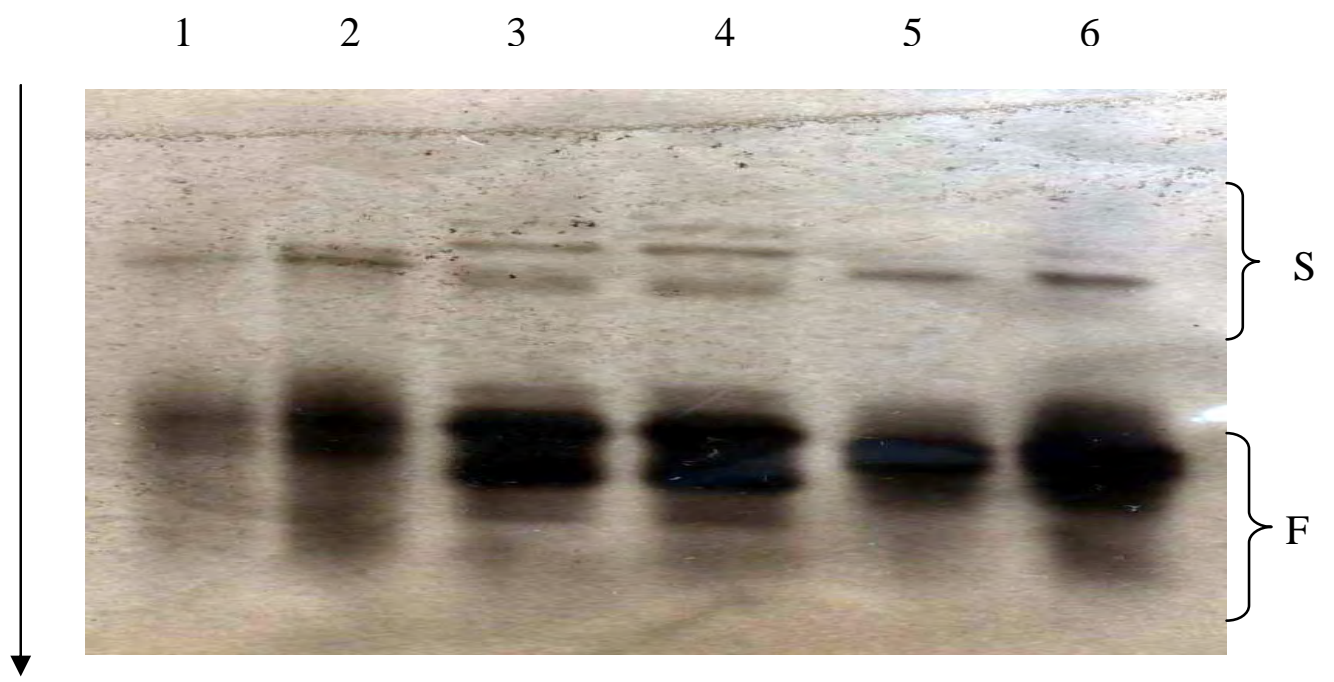

Figure 1: Polyacrylamide gel electrophoresis of esterase isozymes of DBM larvae showing difference between fast-moving (heavily-stained) and slow-moving (lightly-stained) esterase isozymes and the various zymogram patterns of the esterase isozymes within the same DBM population (Mampong).

Lanes 1-6 = carboxylesterase isozymes ; S = Slow-moving esterases, F = Fast-moving esterases; Arrow = direction of gel movement

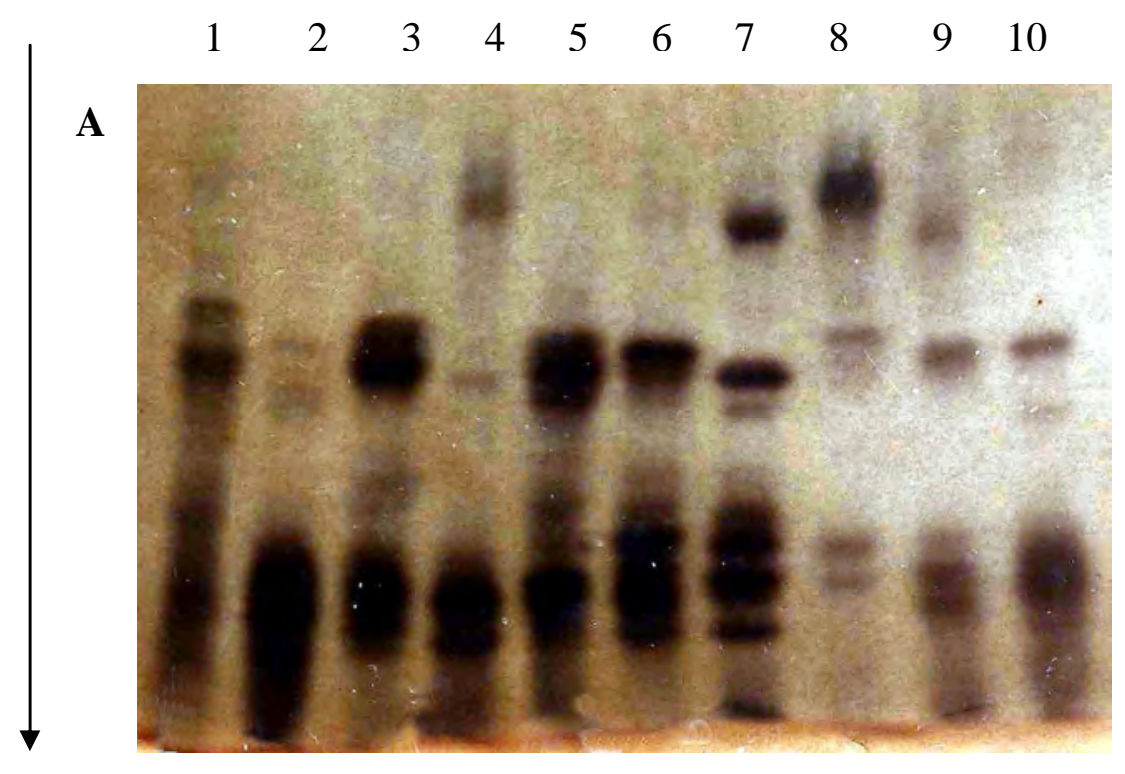




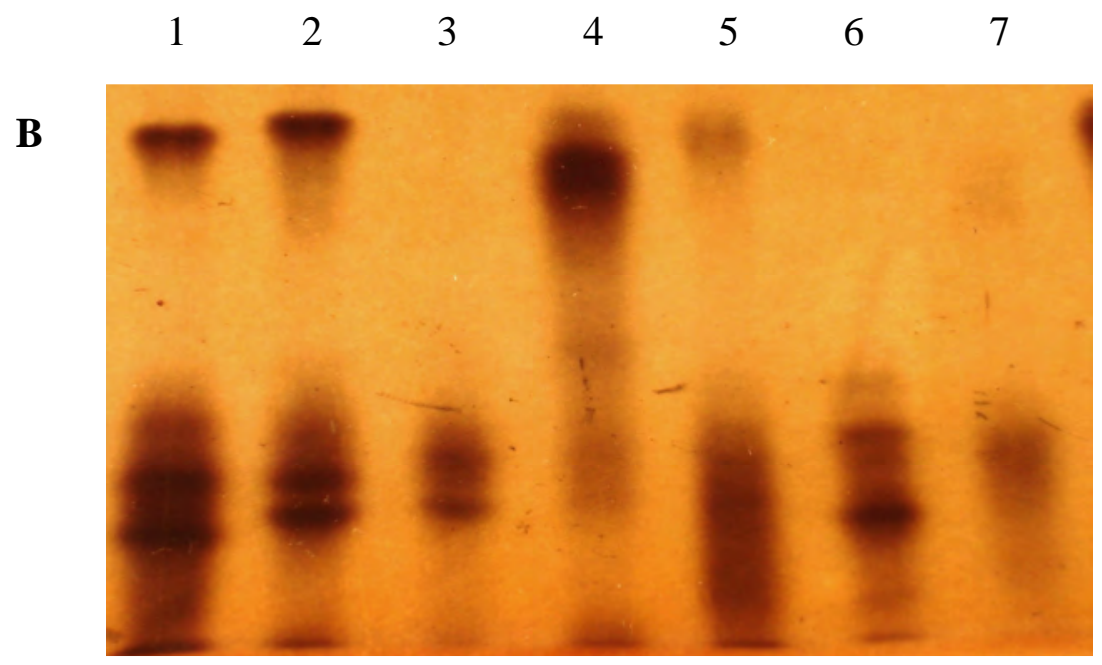

Figure 2: Polyacrylamide gel electrophoresis of DBM larvae showing higher frequency of slow moving esterases in Mampong populations (gel A left), than in a typical Accra suburb site (Airport) (gel B right).

Lanes 1-10 =carboxylesterase isozymes; S = Slow-moving (lightly-stained) esterases, F = Fast- moving (heavily-stained) esterases; Arrow $=$ direction of gel movement.

Table 1: The response of Plutella xylostella (F1) generation of field-collected population to lethal concentrations of active ingredients of the selected insecticides.

\begin{tabular}{|c|c|c|c|c|c|}
\hline Sites & Insecticides & $\begin{array}{c}\mathrm{LC}_{50}\left(\mathrm{mg} \text { litre }^{-1}\right) \\
(95 \% \mathrm{CI})^{* \mathrm{a}}\end{array}$ & $\begin{array}{c}\mathrm{LC}_{95}\left(\mathrm{mg} \text { litre }^{-1}\right) \\
(95 \% \mathrm{CI})\end{array}$ & Slope & $\begin{array}{l}\text { No. of fold } \\
\text { resistance }^{* b}\end{array}$ \\
\hline \multirow[t]{4}{*}{ Airport } & Pawa & $2503.0(2089.1-2941.2)$ & $8527.3(7581.8-9782.2)$ & 0.31 & 102.7 \\
\hline & Dursban & 84034.8(64951.4- 106745.8) & $\begin{array}{c}318928.9(269937.9- \\
390425.8)\end{array}$ & 0.008 & 106.3 \\
\hline & Deltaplan & $572.5(449.8-705.7)$ & $2046.2(1743.4-2505.1)$ & 1.29 & 54.6 \\
\hline & Cypercal & $1819.0(1269.5-2379.7)$ & $8565.2(7343.5-10319.7)$ & 0.24 & 85.7 \\
\hline \multirow[t]{4}{*}{ Madina } & Pawa & $2088.5(1868.0-2335.7)$ & $6355.0(5764.2-7099.7)$ & 0.53 & 76.6 \\
\hline & Dursban & 74617.4(62046.7 -91825.9) & $\begin{array}{c}222920.4(187335.3- \\
276813.5)\end{array}$ & 0.01 & 74.3 \\
\hline & Deltaplan & $385.8(345.0-433.5)$ & 1036.5 (916.2-1206.9) & 3.48 & 27.6 \\
\hline & Cypercal & $2475.0(1856.1-3106.0)$ & $8056.0(6947.7-9642.4)$ & 0.34 & 80.6 \\
\hline \multirow[t]{4}{*}{ Dzorwulu } & Pawa & $2923.5(2585.5-3289.5)$ & $8328.4(7586.5-9249.4)$ & 0.35 & 100.3 \\
\hline & Dursban & $\begin{array}{c}170573.3(141716.8- \\
206364.1)\end{array}$ & $\begin{array}{c}579438.1(495507.5- \\
701492.1)\end{array}$ & 0.006 & 193.2 \\
\hline & Deltaplan & $801.7(664.8-947.9)$ & $2988.4(2640.3-3458.6)$ & 0.84 & 79.7 \\
\hline & Cypercal & $2714.2(2233.8-3242.9)$ & $8188.1(7142.9-9650.9)$ & 0.36 & 81.9 \\
\hline \multirow[t]{4}{*}{ Mampong } & Pawa & $1759.1(1544.5-2022.0)$ & $4802.7(4204.0-5648.9)$ & 0.38 & 57.9 \\
\hline & Dursban & 85496.6(71545.6- 101774.6) & $\begin{array}{c}342873.2(297265.1- \\
407180.6)\end{array}$ & 0.007 & 114.3 \\
\hline & Deltaplan & $497.00(431.0-564.4)$ & $1543.4(1361.4-1807.2)$ & 2.25 & 41.2 \\
\hline & Cypercal & $2274.9(1905.3-2726.3)$ & $5462.9(4685.6-6616.3)$ & 0.31 & 54.6 \\
\hline
\end{tabular}

*a $-95 \%$ CI is $95 \%$ confidence interval in parenthesis

*b- Fold resistance refers to $\mathrm{LC}_{95}$ as a proportion of recommended dosage (expected to give $95 \%$ mortality)

Active ingredients for Pawa [Lambda-cyhalothrin], Cypercal [Cypermethrin], Deltaplan [Deltamethrin] and Dursban

[Chlorpyrifos-methyl]. The insects were reared on insecticide free cabbage. 
Table 2: Carboxylesterase activity of DBM populations in cabbage farms in Mampong-Akuapem and Accra suburbs.

\begin{tabular}{lcc}
\hline Population/Site & \multicolumn{2}{c}{$\begin{array}{c}\text { Esterases activity, mean }(+\mathbf{S . E}) \\
(\boldsymbol{\mu} \mathbf{m o l} / \mathbf{m i n} / \mathbf{m g} \text { protein })\end{array}$} \\
\cline { 2 - 3 } & $\boldsymbol{\alpha}$-naphthylesterase & $\boldsymbol{\beta}$-naphthylesterase \\
\hline Mampong-Akuapem & $9.55 \pm 1.25$ & $49.3 \pm 10.46$ \\
Madina & $1.55 \pm 0.40$ & $2.05 \pm 0.99$ \\
Airport & $1.05 \pm 0.25$ & $1.26 \pm 0.80$ \\
Dzorwulu & $1.49 \pm 0.24$ & $0.62 \pm 0.51$ \\
\hline
\end{tabular}

The insects were reared on insecticide free cabbage

Table 3: Correlation coefficients for relationship between fold resistance and mean activities of $\alpha$ - and $\beta$ - carboxylesterases for Accra sites.

\begin{tabular}{lcc}
\hline Insecticides & $\boldsymbol{\alpha}$-esterase & $\boldsymbol{\beta}$-esterase \\
Pawa & $0.12(\mathrm{p} 0.23)$ & $-0.90(\mathrm{p} \mathrm{0.30)}$ \\
Cypercal & $-0.56(\mathrm{p} \mathrm{0.62)}$ & $-0.38(\mathrm{p} \mathrm{0.75)}$ \\
Deltaplan & $0.65(\mathrm{p} \mathrm{0.55)}$ & $-0.99(\mathrm{p} 0.08)$ \\
Dursban & $0.83(\mathrm{p} 0.37)$ & $-0.92(\mathrm{p} 0.26)$ \\
\hline
\end{tabular}

\section{DISCUSSION}

A preliminary survey showed that insect pests were a major constraint to cabbage production. DBM was considered a key pest of cabbage causing damage in $73 \%$ of the farms surveyed (Odhiambo, 2005). The increasing pest infestation could be attributed to improper agronomic practices in the farms, such as spraying sub-lethal or high dosages at high frequencies, use of insecticide mixtures, poor irrigation methods, monoculture and poor field sanitation (Odhiambo, 2005).

Susceptibility study showed that DBM was highly resistant to all the insecticides assayed. The stability of resistance to synthetic insecticides (Shelton and Zhao, 2004), was substantiated from the study. This was shown by recording very high resistance to insecticides assayed even in areas where those particular formulations were not currently in use. For example, Dursban recorded very high level of resistance (193 fold) in Dzorwulu, although only a few farmers were currently using it. Similarly, DBM population in Airport area showed the highest resistance to cypermethrin although currently Cydimsuper, a mixture of cypermethrin $(36 \mathrm{~g} / \mathrm{L})$ and dimethoate $(400$ $\mathrm{g} / \mathrm{L}$ ), was in common use in the area and not cypermethrin alone. This showed not only the stability of resistance to the insecticides but also that multiple resistance and crossresistance are major contributors to low efficacy of most conventional insecticides to DBM.

Bioassays conducted to test for probable existence of cross- and/or multiple-resistance among the DBM populations, revealed the presence of cross-resistance among the pyrethroids assayed, and a strong multipleresistance to the pyrethroids and organophosphates. DBM populations showed resistance to both Pawa (pyrethroid) and Dursban (organophosphate) in Mampong and Dzorwulu and therefore the two should not be used in rotation. The low resistance recorded 
for Deltaplan (pyrethroid) in Madina may suggest that it could be judiciously used to control DBM populations that had developed resistance to Pawa. However this was not the case for Airport area where Deltaplan only recorded $30 \%$ mortality on the same DBM population. This confirmed the findings by Lin (1988) that DBM resistance covers all the major groups of insecticides. As a result, insects resistant to pyrethroids may develop resistance to organophosphates even without exposure to the latter group of insecticides.

The high carboxylesterase activity observed in DBM indicates some level of resistance, a likely consequence of a long period of exposure to organophosphates and pyrethroids. Mampong recorded very high activity of the two enzymes followed by Madina and Dzorwulu populations. The grand mean recorded for $\alpha$-and $\beta$-naphthyl esterases for DBM populations from Accra suburbs were $\quad 1.63 \mu \mathrm{mol} / \mathrm{min} / \mathrm{mg}$ and 0.92 $\mu \mathrm{mol} / \mathrm{min} / \mathrm{mg}$, respectively. In comparison to the work of Kaiwa (2000), which recorded means of $1.50 \mu \mathrm{mol} / \mathrm{min} / \mathrm{mg}$ and 1.20 $\mu \mathrm{mol} / \mathrm{min} / \mathrm{mg}$ for $\alpha$ - and $\beta$-naphthyl esterase activities respectively, the results of the present studies for Accra suburbs were not significantly different. Higher $\alpha$-naphthyl esterase activity was recorded for Accra suburb sites confirming findings of Kaiwa (2000) on carboxylesterase activity in DBM in Accra suburbs.

Results obtained for Accra suburbs indicated that $\alpha$-esterase activities generally positively correlated with fold resistance to both deltamethrin and chlorpyrifos-methyl. On the other hand $\beta$-esterase activity strongly correlated negatively with fold resistance for all the pyrethroids (cypermethrin, lambdacyhalothrin, deltamethrin) and organophosphate (chlorpyrifos-methyl) used. Negative correlation is indicative of susceptibility. The relatively higher level of $\beta$-esterase activity compared with $\alpha$-esterase recorded for Mampong samples may explain the higher susceptibility of the Mampong DBM population to pyrethroids and organophosphates.
The results of survey conducted on insecticide use patterns (Odhiambo, 2005) indicated higher use of the organophosphates and pyrethroids in Accra suburbs than in Mampong, and this may account for the higher resistance of DBM to all the insecticides bioassayed particularly for the Accra populations (Table 2). Since carboxylesterase activities obtained cannot fully account for the resistance levels recorded in the study, other enzymes systems such as oxidases and glutathione-S-transferases may also be involved in DBM resistance as has been reported elsewhere (Maa et al., 1997; Eziah et al., 2008).

Carboxylesterase enzymes were also shown to have wide variations in activity even from same site, especially in Mampong. This may suggest development of resistance at different times under selection by different insecticides. In the zymogram studies of esterase isozymes, two main groups of esterase bands were identified, a fast moving upper zone and a slow moving lower zone. Based on the preliminary characterization of esterases of DBM (Maa et al., 1990), high level of resistance was found to be more likely associated with slow moving esterases, which are considered to be more important in resistance monitoring than fast moving esterases. The esterase isozymes combined in different patterns and intensities to give varying levels of resistance, although negative correlation between the banding patterns and resistance had been reported (Maa et al., 1997). These workers, however, argued that DBM had developed multiple resistance mechanisms, and its resistance to organophosphates and pyrethroids did not only depend on hydrolysis of these insecticides. The work of Owusu et al. (1995) on aphids also emphasized that, band intensities rather than numbers were likely to be the principal factors determining the quantity of resistant-linked enzymes produced by an individual insect.

DBM population in MampongAkuapem showed higher frequency of slow moving esterases than the Accra suburb sites 
(Fig. 2), which had majority of the zymograms with the fast moving esterases, associated with low resistance. This confirms the findings of the enzyme assays, for which the Mampong DBM population had higher $\alpha$ and $\beta$-carboxylesterase activities than the Accra sites. Mampong DBM population showed a variety of zymogram patterns (Fig.1). This pattern was also shown by the enzyme assay, which depicted wide deviations in activity, indicative of wide qualitative differences within the same population. Comparatively, Madina DBM population had higher frequency of slow moving esterases while Dzorwulu was shown to record the least frequency. This confirmed the results of the carboxylesterases assay, which showed Dzorwulu population to be fairly susceptible particularly, as demonstrated by the rather low $\beta$-esterase activity. The exhibition of heterogeneous forms of electrophoretic banding patterns by resistant DBM strains suggest that resistance might have developed over different periods of time under varying degrees of pesticide selection pressure. This supports the view that resistance development is rapid when selection pressure exerted by insecticide is widespread and continuous (Brown, 1964). It is suggested that the use of the conventional insecticides in rotation with dipel (formulations of Bacillus thuringiensis) could help reduce the selection pressure of these insecticides and preserve susceptible genes in DBM population.

\section{Conclusion}

Susceptibility study showed that DBM was highly resistant to all the insecticides assayed, viz. the pyrethroids - cypermethrin, lambdacyhalothrin and deltamethrin, and the organophosphate - chlorpyrifos-methyl, even in areas where these particular formulations were not currently in use. Bioassays on these insecticides revealed the presence of crossresistance among the pyrethroids assayed, and a strong multiple-resistance to the pyrethroids and organophosphates.

The activity of carboxylesterases was studied as indicator of resistance. However, carboxylesterase activities obtained could not fully account for the resistance levels recorded in the present study, leaving the possibility of involvement of other enzyme systems such as oxidases and glutathione-S-transferases.

For effective management of DBM, there is need to delay resistance development, which can be achieved by starting resistance management before resistance is detected and also by strategically applying insecticides at the most vulnerable developmental stages of the insect. The use of insecticides with short persistence is preferred so as to avoid prolonged exposure of the insects to the insecticides, which is a prerequisite for resistance development. These insecticides should also be used intermittently at the lowest possible effective dosages/rates, while susceptibility of DBM and other pests to all the insecticides, should be monitored on a regular basis in the representative fields.

\section{ACKNOWLEDGMENTS}

This work was supported by grant from DAAD, Germany. We thank Prof E. O. Owusu of the Department of Zoology, University of Ghana for the provision of fast blue B salt.

\section{REFERENCES}

Brempong-Yeboah CY. 1992. Report: Workshop on vegetable production in the Accra Plains. Crop Science Department, University of Ghana, Legon.

Brown AWA. 1964. Insect resistance. Part IV: countermeasures for resistance. Farm Chemicals., 127(1): 58-69.

Eziah VY, Rose HA, Clift AD, Mansfield S. 2008. Susceptibility of four populations of the diamondback moth Plutella xylostellaL.(Lepidoptera:Yponomeutidae) to six insecticides in the Sydney region, New South Wales, Australia. Australian J. Entomology, 47: 355-360.

Finney DJ. 1971. Probit Analysis: A Statistical Treatment of the Sigmoid Response Curve. Cambridge University Press: Cambridge; 333. 
GTZ (German Agency for Technical Cooperation). 1979. Pesticide Residues Problems in the Third World. GTZ; 60.

Hama H. 1987. Insensitivity of acetylcholinesterase in phenothoate resistant diamondback moth, Plutella xylostella L. (Lepidoptera: Yponomuetidae). Japanese J. Appl. Entomol. Zoology, 22: 116-118.

Joia K, Suri S., Udeaan AS. 2004. Baseline susceptibility of diamondback moth, Plutella xylostella (Linn.), to new insecticides. Department of Entomology Punjab Agricultural University Luthiana, 1410004 India.

Kaiwa FJ. 2000. Studies on the biology and activity levels of carboxylesterase as an indicator of insecticide resistance in population of diamondback moth, Plutella xylostella (L.) (Lepidoptera: Plutellidae) on cabbage in Ghana. MPhil thesis, University of Ghana, Legon, pp 87.

Kao C, Hung C, Sun C. 1989. Parathion and methyl parathion resistance in diamondback moth (Lepidoptera: Plutellidae). Larvae. J. Econ. Entomol., 82(5): 1299-1304.

Kao C, Cheng EY. 2001. Insecticide resistance in Plutella xylostella L. XI. Resistance to newly-introduced insecticides in Taiwan. J. Agric. Res. China, 50(4): 80-89.

Lin JG. 1988. Teflubenzuron resistance and microsomal monoxygenases in larvae of the diamondback moth. B.S. thesis, National Chuang-Hsing University, Taichung, Taiwan, Republic of China, pp 72.

Liu MY, Sun CN. 1984. Rearing diamondback moth (Lepidoptera: Yponomeutidae) on rape seedlings by a modification of the Koshihara and Yamada method. J. Econ. Entomol. 75: 153-155.

Lowry OH, Rosebrough NJ, Farr AL, Randall RJ. 1951. Protein measurement with the Folin Phenol Reagent. J. Biol. Chem., 193: $265-276$.
Maa WC, Chuang ML. 1983. Esterases of Diamondback moth (Plutella xylostella L.): Enzymatic properties of larval esterases. Bull. Inst. Zool. Acad. Sin., 22: 123-131.

Maa WC, Lee S, Guh SH, Wang CM, Hou, JW. 1990. Esterase zymograms as an assay for detection of population of Diamondback moth. In Proceedings, $2^{\text {nd }}$ International Workshop. Talekar NS (ed). Asian Vegetable Research and Development Center, Shanhua, Taiwan.

Maa CJW, Liu JF, Tzau YY, Ch'eng CH. 1997. Involvement of acetylcholinesterase in malathion-resistance of the diamondback moth. In The management of diamondback moth and other crucifer pests. Proceedings of the Third International Workshop. Malaysia Agriculture Research, Development Institute/Malaysia Plant Protection Society. Kuala Lumpur, Malaysia.

Moharil MP, Wadegaonkar PA, Rao NGV, Tikar SN, Rai MK, Nimbalkar SA. 2008. Detection of a carboxylesterase-mediated resistance mechanism in Plutellaxylostella (L.) by diagnostic microplate assay. Research J. Agric. Biol. Sci., 4(6): 623-629.

Ninsin KD. 1997. Insecticide use patterns and residue levels in cabbage (Brassica oleracea Var capitata L.) within the Accra-Tema metropolitan area of Ghana. MPhil. thesis, University of Ghana, Legon. pp 85.

Ninsin KD. 2004. Acetamiprid resistance and cross-resistance in the diamondback moth, Plutella xyllostella. Pest Manag. Sci., 60: 839-841.

Noppun V, Miyata T, Saito T. 1987. Insensitivity of acetylcholinesterase in phenothoate resistant diamondback moth, Plutella xylostella L., against insecticide. J. Insecticide Sci., 8: 595-599.

Odhiambo JAO. 2005. Insecticide resistance in diamondback moth, Plutella xyllostella from selected cabbage farms associated with pyrethroid and organophosphate use 
in Southern Ghana. MPhil thesis, University of Ghana. Legon. pp 176.

Osae MY. 2002. Virulence and transmission of an East African Plutella xylostella Granulosis virus (Ply GV- Kenya) in a West African diamondback moth, Plutella xylostella (L.) Lepidoptera: Plutellidae) Population. MPhil thesis, University of Ghana. Legon. 135 pp.

Owusu EO. 1992. Properties of esterases from resistant strain aphid, Aphis gossypii (Homoptera: Aphididae),, Nephotettix cincitiaps Unler (Homoptera: Cincadellidae). MSc thesis. Kochi University, Kochi, Japan.

Owusu EO, Horiike M, Hirano C. 1995. Susceptibility of cotton aphid, Aphis gossypii (Glover) (Homoptera: Aphididae) clones to dichlorvos and its relationship to activity levels of some esterases. Research Representatives (Agriculture), Kochi University, 44: 5967.

Pichon A, Arvanitakis L, Roux O, Kirk AA, Alauzet C, Bordat D, Legal L. 2006. Genetic differentiation among various populations of the diamondback moth, Plutella xylostella (Lepidotera: Yponomeutidae). Bulletin Entomologcal Research, 96: 137-144.

Shelton AM, Zhao JZ. 2004. Insecticides resistance: How we get to avoid it. Department of Entomology, Cornell University, New York State Agricultural
Experiment station, Geneva, NY 14456, USA. pp 7.

Siegfried BD., Scott JG. 1991. Mechanisms responsible for propoxur resistance in the German cockroach. Pestic. Sci., 33: 133146.

Tabashnik BE, Cushing NL, Johnson MW. 1987. Diamondback moth (Lepidoptera: Plutellidae) resistance to insecticides in Hawaii: intra-island variation and crossresistance. J. Econ. Entomology, 83: 1091-1099.

Wright DJ, Iqbal M, Granero F, Ferre J. 1997. A change in a single midgut receptor in the diamondback moth, Plutella xylostella L. is only in part responsible for field resistance to Bacillus thuringiensis subsp. Kurstarki and $B$. thuringiensis subsp. Aizawai. Appl. Environ. Microbiol., 63(5): 1814-1819.

YuXian H, XiuJuan Y, Qiyong W, Yang XJ, Weng QY. 2001. Advances in studies on the insecticide resistance of Plutella xylostella L. and its management. Acta Agriculturae Universitatis Jiangxiensis., 23(3): 320-337.

Zhao JZ, Fan X, Zhao Y. 1994. Comparison of two bioassay techniques for resistance monitoring in Heliothis armigera and Plutella xylostella. Resistant Pest Management Newsletter, 6(1): 14-15. 